Maurice et al., Afr., J. Infect. Dis. (2018) 12 (2): 72-77

https://doi.org/10.21010/ajid.v12i2.12

\title{
RABIES IN A SET OF EIGHT-WEEK OLD PUPPIES IN NIGERIA: THE NEED FOR REVIEW OF CURRENT DOG ANTIRABIES VACCINATION SCHEDULE
}

\section{Nanven Abraham Maurice ${ }^{1}$, Pam Dachung Luka ${ }^{2}$, Magdalene Nanven Maurice ${ }^{3 *}$, Emmanuel Ochefije Ngbede $^{4}$, Ponfa Nden Zhakom ${ }^{5}$, Philip Paul Mshelbwala ${ }^{6}$, Ishaya Sini Tekki ${ }^{4}$, Utibe-Abasi Hilary Udoh $^{7}$, Udoh Akpan Inyang ${ }^{7}$, Nsika Joseph Ekanem ${ }^{7}$, Okon John Ifut ${ }^{7}$, Philip A. Okewole ${ }^{1}$, David Shamaki ${ }^{1}$, Lami Hanatu Lombin ${ }^{8}$}

${ }^{1}$ Department of Diagnostic and Extension, National Veterinary Research Institute, Uyo Laboratory, Akwa Ibom State, Nigeria; ${ }^{2}$ Biotechnology Division, National Veterinary Research Institute, Vom. Plateau State, Nigeria; ${ }^{3}$ Department of Veterinary Microbiology, Faculty of Veterinary Medicine, Ahmadu Bello University, Zaria, Kaduna State, Nigeria; ${ }^{4}$ Department of Pathology and Microbiology, College of Veterinary Medicine, University of Agriculture, Makurdi, Benue State. Nigeria; ${ }^{5}$ Rabies Laboratory, National Veterinary Research Institute, Vom., Plateau State, Nigeria; ${ }^{6}$ Department of Veterinary Medicine, Faculty of Veterinary Medicine, University of Abuja, Nigeria; ${ }^{7}$ Department of Animal Science, Faculty of Agriculture, University of Uyo, Akwa Ibom State, Nigeria; ${ }^{8}$ Faculty of Veterinary Medicine, University of Jos, Plateau State Nigeria.

*Corresponding Author's E-mail: mnanven@ hotmail.com

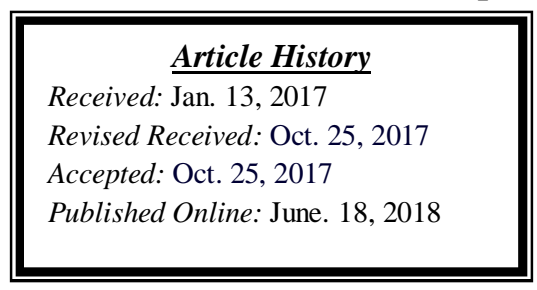

\begin{abstract}
Background: Rabies is endemic in Nigeria with clinical cases reported mainly in dogs and occasionally in livestock from all the geo-ecological zones of the country. Detection of rabies virus antigen in puppies at the age of five to ten weeks and in apparently healthy dogs shedding the virus in their saliva have been reported in some parts of Nigeria.

Material and Method: This report describes a clinical rabies in a set of eight weeks old puppies confirmed by antigen detection using the direct fluorescent antibody test (DFAT), the direct rapid immunohistochemical test (DRIT), and RT-PCR.

Results: it was positive for all test used including the RT-PCR which amplified at $750 \mathrm{bp}$ from the gel electrophoresis. Conclusion: Occurrence of rabies in puppies of this age, within which they are acquired and owned by other unsuspecting members of the public, is of grave public health consequences. People that love puppies, especially children, who are fond of carrying and playing with them, are also faced with the risk of exposure to rabies. Consequently, review of the existing dog antirabies vaccination schedule at twelve weeks of age in Nigeria, is recommended to ensure effective immunization of this age group of dogs and for the overall safety of the vulnerable members of the public.
\end{abstract}

Keywords: Puppies, Rabies, Vaccination schedule, DFAT, DRIT, RT-PCR, Nigeria.

\section{Introduction}

Rabies is caused by a single-stranded, RNA virus that belongs to the genus Lyssavirus and family Rhabdoviridae (Walker et al., 2015). The highly neurotropic rabies virus causes a rapidly progressive encephalomyelitis or meningoencephalitis (Tekki et al., 2014). Rabies affects all mammals but primarily domestic and wild dogs; other hosts include foxes, jackals, skunks, mongooses, raccoons and bats (Nandi and Kumar, 2011; Noah et al., 1998). However, there are reports of rabies in livestock like cattle, sheep and goats in Nigeria (Ojo and Adeoye, 1967; Okoh, 1981; Bello et al., 2007; Promed, 2012; Tekki et al., 2014). RABV persists in Eastern Europe and border crossings of rabid foxes resulting in the reintroduction of rabies in Italy (2008), Macedonia (2011) and Greece (2012). In Western Europe, the indigenous rabies reserves are now limited to bats, for EBLV-1 and EBLV-2. Europe is facing with cases of imported rabies, mostly linked to the illegal introduction of animals from countries not free of rabies: 21 cases (dogs or cats) between 2001 and 2013 (Kirandjiski et al., 2012; Tsiodras et al., 2013). However some countries in the United Kingdom, New Zealand, Hawaii, Australia, Japan and Antarctica are free from the rabies virus through 72 
successful eradication programs or historically rabies have not been reported in these region (Hoffmann et al., 2010). Rabies has persisted in Asia and Africa where the burden is highest globally. In Nigeria, exposure to rabies through bites from rabid dog accounts for 100\% of the confirmed cases (Garba et al., 2010; Ameh et al., 2014; Odeh et al., 2014). The epidemiology of rabies has been described in Nigeria with dogs as the reservoir of the disease (Oduye and Aghomo, 1985; Garba et al., 2010; Ameh et al., 2014; Odeh et al., 2014).

\section{Materials and Methods}

On July 16, 2015, a client presented a six-year bitch which just whelped for the sixth time with the set of three puppies to the National Veterinary Research Institute (NVRI) Outstation, Uyo, Akwa Ibom State, Nigeria for routines check-up. Two of the puppies were female while one was a male. The owner also had a four years old male mongrel in the house.

On September 3, 2015, the dog owner reported to the NVRI Laboratory that one of the female puppies went out of the house-hold gate early in the morning and was bitten on the upper and lower jaws by a stray dog suspected to be rabid. The bite-wound was simply dressed and $0.3 \mathrm{ml}$ of antibiotics (Penstrep) was administered by parenteral route to the puppy per day for five days to facilitate wound healing by controlling secondary bacterial infections. A couple of weeks later, the owner reported abnormal behaviours such as aggression, hyper salivation in the puppy. It was also reported to have bitten other puppies in the kennel before it died on September 21, 2015 at 5:15 pm, three weeks after it had been bitten by the rabid suspect stray dog. Subsequently, the remaining two puppies also died at eight weeks old. The case was tentatively diagnosed as Rabies. The heads of the two puppies that died later were severed and shipped on ice to the Rabies laboratory, NVRI, Vom, Plateau State, for confirmation, the animal's brain was collected by opening the skull as described (Barrat and Blanco, 1998).

Ethical approval: All applicable international, national, and/or institutional guidelines for the care and use of animals were followed. An Institutional Ethical Clearance - NVRI AUCC REF No: AEC/02/23/15 was obtained from the Animal Use and Care Committee of National Veterinary Research Institute, Vom, Nigeria, to carry out the study.

\section{Laboratory Diagnosis}

Direct Fluorescent Anti-body Test (DFAT): DFAT was carried out as described by CDC (2006).

Direct Rapid Immuno-histochemical Test (DRIT): DRIT was performed on formalin fixed impression smears of the brain specimens as described by CDC (2011).

\section{RNA Extraction and RT-PCR}

Sample preparation: Approximately one gram of brain tissue from each sample was weighed and homogenized using a pestle and mortar. After homogenizing, $10 \%$ tissue suspension was made in PBS, pH 7.2 and clarified in a refrigerated centrifuge at $10,000 \mathrm{rpm}$ for 5 minutes. The supernatant was decanted into a sterile tube and kept at $4{ }^{\circ} \mathrm{C}$ for RNA extraction. RNA extraction: Total RNA was extracted using QIAamp Viral RNA Mini kit following the manufacturer's guidelines. Extracted RNA was kept briefly at $4{ }^{\circ} \mathrm{C}$ pending cDNA synthesis. cDNA synthesis and conventional RT-PCR: Reverse transcription and subsequent amplification were performed on all samples, using a previously described protocol (Markotter et al., 2006) with primers 001lys and 550B. RT-PCR was performed on samples using the following protocol. One microliter of the primary amplified PCR product was added to a final

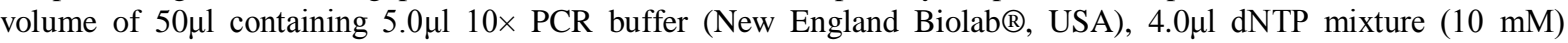
(Promega), 10 pmol forward primer 001lys and reverse primer 550B, and 0.5 $\mu$ l Taq polymerase $(2 \mathrm{U} / \mu \mathrm{l}$; New England Biolab®, USA). Amplification was performed on a GeneAmp PCR System 9700 (Applied Biosystems, Germany). After denaturation at $94^{\circ} \mathrm{C}$ for $1 \mathrm{~min}$, reactions were cycled 40 times at $94^{\circ} \mathrm{C}$ for $30 \mathrm{~s}, 37^{\circ} \mathrm{C}$ for $30 \mathrm{~s}$, and $72^{\circ} \mathrm{C}$ for $90 \mathrm{~s}$, with final extension at $72^{\circ} \mathrm{C}$ for $10 \mathrm{~min}$. Products were visualized on $1 \%$ agarose gels stained with ethidium bromide.

\section{Results and Discussion}

Apple-green fluorescing rabies viral particles were present in the brain sample smears processed by FAT (Figure 1). Similarly, DRIT result revealed red inclusions within bluish cell bodies as shown in Figure 2 below, indicating that the sample was positive for rabies. The presence of the virus was also confirmed by RT-PCR (Figure 3). 


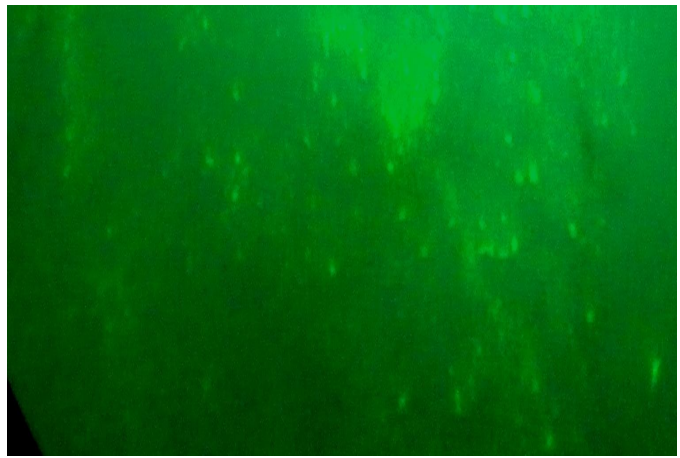

Figure 1. DFAT positive sample

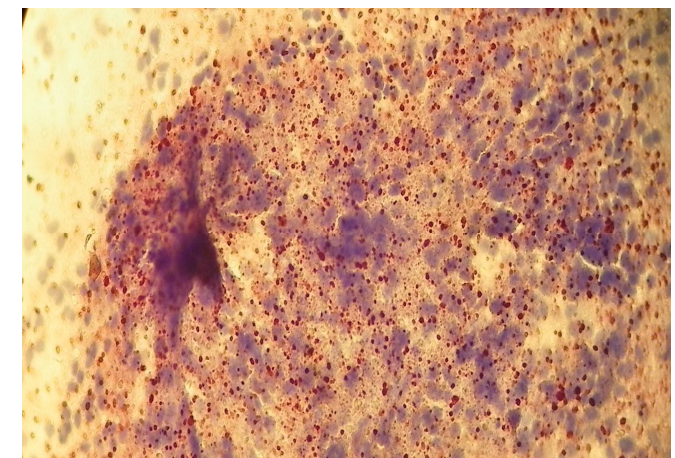

Figure 2. DRIT positive sample

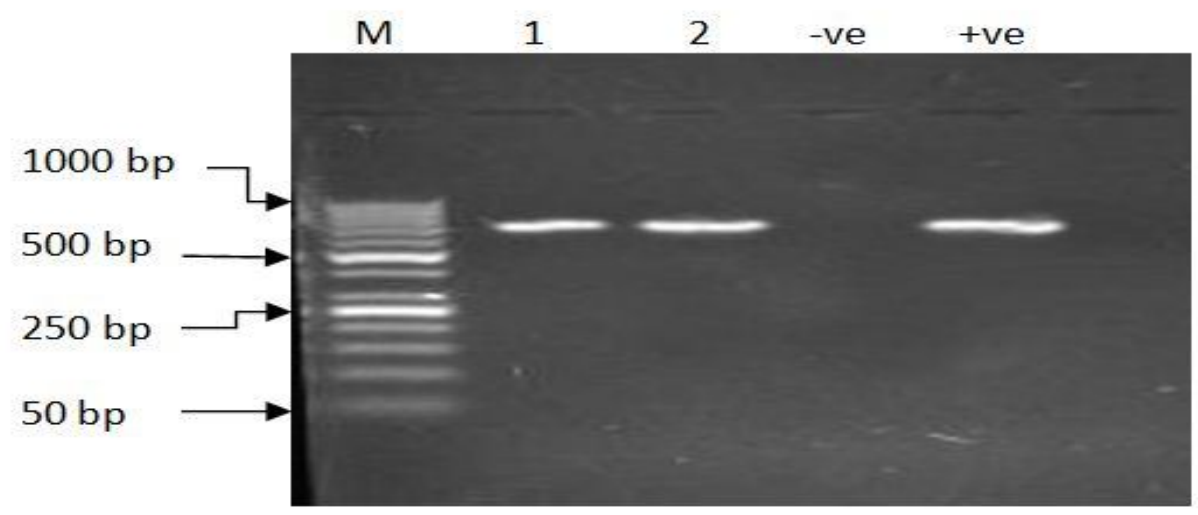

Figure 3: M- Molecular marker, Lane 1 and 2 samples, -Ve- Negative control, +Ve- positive control. The samples were amplified at $750 \mathrm{bp}$ from the gel electrophoresis.

Rabies is endemic in Nigeria and this has been attributed to dog-to-dog, dog-to-livestock and dog-to-human transmission (Bello et al., 2007; Aworh et al., 2011; Abubakar et al., 2012; Hambolu et al., 2013 Tekki et al., 2014). Generally, effective control of the disease can best be achieved by achieving a minimum of $70 \%$ vaccination coverage of dogs (Coleman and Dye, 1996). This high coverage is especially important to maintain the population level immunity and to break transmission of rabies in situations where stray dogs predominate (Hambolu et al., 2014). In Nigeria, all dogs aged three months and older are vaccinated against rabies (Umoh et al., 1988), with the assumption that younger ones are protected by maternal derived antibody (MDAs). Occurrence of rabies in puppies of less than three months of age in this report is therefore of a serious public health concern. Although the general public is at risk of infection, the strong attachment of most owners and other lovers of dogs, especially children, to puppies or dogs generally, increase the risk of human infection with the causative virus. This therefore calls for review of dog vaccination schedule for effective control of rabies in Nigeria. In previous studies, rabies has been reported in a ten weeks old puppy in Uyo, Akwa Ibom State (Offiong et al., 2013) and in eight weeks, six weeks and five weeks old puppies in parts of Nigeria (Adeyanju and Addo, 1977; Onunkwo et al., 1980; Kujul et al., 2010). Outside Nigeria, rabies has been reported in a 10 weeks old male border collie-cross puppy in Saskatoon in Western College of Veterinary Medicine Teaching Hospital (Jennifer et al., 2007). It is obvious therefore that puppies infected with rabies virus are veritable sources of infection to man and other animals as they would eventually be disposed of by the dog breeder and acquired by new owners.

Demonstration of rabies virus by standard laboratory techniques viz.: DFAT (Figure 1), DRIT (Figure 2) and Amplification (750bp) of a region of the $\mathrm{N}$ gene using oligo primers 001lys and 550B as described by Markotter et al., (2006) (Figure 3) in the brain samples of the puppies in the present study; coupled with the previous reports above, pose a serious challenge to Veterinarians and other stakeholders in Nigeria in their efforts in achievement of the elimination of death due to dog rabies by 2030 (global Alliance for the Control of Rabies, 2015). 
One wonders what the dynamics of the epidemiology of the virus is in domestic dogs in Nigeria currently, considering the occurrences of rabies in puppies at far below the recommended age of vaccination and the reported detection of rabies virus or some Lyssaviruses in apparently healthy dogs in parts of Nigeria (Aliyu et al., 2010; Mshelbwala et al., 2013; Hambolu et al., 2013; Tekki et al., 2014).

Most of the puppies affected by rabies in Nigeria so far have been from mongrel bitches which are usually either not vaccinated or improperly vaccinated against rabies (because of the poor knowledge and attitude on the importance of vaccination and who is qualified to administer vaccine. This is in addition to the fact that majority of the owners of Mongrel are poor in the society). In the present cases however, the bitch had been vaccinated against rabies before having the puppies in question. Although the bitch was not screened for rabies virus neutralizing antibody, there was an indication that the bitch was either not immunized even though vaccinated, hence the puppies had no maternal derived antibody (MDAs), or the level of the MDAs was too low to protect them. Vaccine failure had occurred in 2.5 of every million doses in Nigeria as cited by Kujul et al. (2010) who reported the occurrence of rabies in puppies of a bitch that had previously been vaccinated against rabies. The commonest cause of non-seroconversion and protection of a vaccinated individual against rabies is vaccine failure, which is a reoccurring phenomenon in Africa and Asia. This is reported to have been caused by reduced antigenicity of the vaccines (Webster, 1939), largely due to poor handling (Oladokun et al., 2010) and improper administration of the vaccines (Tierkel, et al., 1953). Possible changes in the strains of rabies vaccine viruses during stages of propagation in different animal hosts had been adjudged to reduce their usefulness as vaccines (Wiktor, et al., 1969). Therefore, to ensure maintenance of vaccine potency for effective immunization of dogs, there is need to carry out proper monitoring of handling and administration of rabies vaccines as loss of viability resulting from improper handling in the field has been reported in Nigeria (Oladokun et al., 2010).

If the dam of the affected puppies was protected and had passed adequate MDAs to the puppies, it then means that the puppies succumbed because the MDAs had waned at the time they were exposed. It is also possible that the vaccine was no longer potent at the time of administration resulting in vaccine failure and thus no MDAs to confer passive immunity were transferred to the puppies increasing their susceptibility. This finding corroborates the reports from the field that show increase in the incidence of dog rabies in Uyo, Akwa Ibom State which, according to Offiong et al. (2013) is exacerbated by the high rate of handling and consumption of dog meat as a special delicacy among the natives of the State. Most of the trade dogs slaughtered and consumed in Uyo are unvaccinated stray dogs captured from various places in northern part of the country. The dogs are usually transported together under stressful conditions to major holding centres in Uyo, warranting fighting and transmission of pathogens including rabies virus from infected to susceptible ones. From the local holding centres, the dogs are distributed amongst various slaughter spots without screening for rabies and fitness for slaughter (Ehimiyein et al., 2014). This will certainly increase the risk of human exposure to rabies in the state if necessary measures are not taken to by stakeholders to enforce compulsory vaccination of dogs against rabies.

\section{Conclusion}

Although rabies is endemic in Nigeria, detection of the virus in puppies before the recommended age of vaccination suggests that there is a change in the trend of the epidemiology of the disease. Evidences of rabies in puppies that are younger than the official vaccination age in Nigeria (3 months) give credence to the need for change of the policy on dog vaccination against rabies in order to protect this age group of dogs and the general public from infection with rabies.

This therefore calls for review of dog vaccination schedule for effective control of rabies in Nigeria. Annual rabies mass vaccination campaign in addition to improved public health enlightenment campaigns on the devastating effect of rabies and the importance vaccination in the prevention and control of rabies are recommended.

Conflict of Interest: The authors declare that they have no conflict of interest.

\section{Acknowledgements}

We thank Miss Blessing Jackson, the owner of the dog, for her cooperation during field investigation and sample collection. We appreciate the contributions of the technical personnel of the rabies laboratory in the diagnosis and the Management of NVRI, Vom for the enabling environment to carry out and publish the work.

\section{References}

1. Abubakar, S.A., and Bakari, A.G. (2012). Incidence of dog bite injuries and clinical rabies in a tertiary health care institution: A 10-years retrospective study. Annals of African Medicine. 11(2): 108-111.

2. Adeyanju, J.B. and Addo, P.B. (1977). Rabies in an eight week-old puppy. Veterinary Record. 101:101(2):38

3. Aliyu, T.B., De, N., Yenda, E.N., and Lynn, M (2010). Prevalence of rabies virus antigen in apparently healthy dogs in yola. Nigeria. Researcher 2(2). 
4. Ameh, V.O., Dzikwi, A.A., and Umoh, J.U. (2014). Assessment of knowledge, attitude and practices of dog owners to canine rabies in Wukari Metropolis, Taraba State. Nigeria. Global Journal of Health Science, 6, 5:226-240.

5. Aworh, M. K., Nwosoh, C. I., Ajumobi, O. O., Okewole, P. A., Okolocha, E.C., Akanbi, B. O., and Nguku, P (2011). A retrospective study of rabies cases reported at Vom Christian Hospital, Plateau State. Nigeria. Nigeria Veterinary Journal 32(4), 366-370.

6. Barrat, J. and Blancou, J. (1998). Technique simplifiee de prelevement, de conditinnment et dexpedition de matere cerebrale pour le diagnostic de rage.

7. Bello, M., Lukshi, B.M., Usman, B. 2007. A fifteen-year retrospective study of the prevalence of rabies in Bauchi State, Nigeria. Nigerian Veterinary Journal 28 (2) 18-23.

8. CDC, (2006). Protocol for Postmortem Diagnosis of Rabies in Animals by Direct Fluorescent Antibody Testing, A Minimum Standard for Rabies Diagnosis in the United States. Available: http://www.cdc.gov/ncidod/dvrd/rabies/Professional/publications/DFA_diagnosis/DFA_protocol-b htm 2006.

9. CDC, (2011). Protocol for postmortem diagnosis of Rabies in animals by Direct Fluorescent Antibody Technique. Retrieved from www.cdc.gov/rabies/pdf/rabiesdfaspv2.pdf.

10. Coleman, P.G. and Dye, C. (1996). Immunization coverage required to prevent outbreaks of dog rabies. Vaccine 14(3): 185 - 186.

11. Ehimiyein A, Audu S and Ehimiyein I (2014). The role of dog Trading and Slaughter for Meat in Rabies Epidemiology with Special Reference to Nigeria- A Review. Journal of Experimental Biology and Agricultural Sciences, 2(2).

12. Garba, A., Oboegbulem, S. I., Junaidu, A.U., Magaji, A. A., Umoh, J. U., Ahmed, A., Danbirni, S., Chiko, K. L., Habu, A. K. and Masdooq, A. A. (2010). Rabies virus antigen in the brains of apparently healthy slaughtered dogs in Sokoto and Katsina States, Nigeria. Nigerian Journal of Parasitology. 31(2): 123-125.

13. Global Alliance for Rabies Control (2015).New campaign seeks an end to rabies deaths in 15 years https://rabiesalliance.org/media/press/new-campaign-seeks-an-end-to-rabies-deaths-in-15years\#sthash.q4L4AYcv.dpuf

14. Hambolu, S.E., Dzikwi, A.A., Kwaga, K.P., Kazeem, H.M., Umoh, J.U., and Hambolu, D.A., (2013). Rabies and dog bites cases in Lagos State, Nigeria. Prevalence and retrospective studies (2006-2011). Global Journal of Health Science, 27; 6 (1) 107-114.

15. Hambolu, S.E., Dzikwi, A.A., Kwaga, J.K.P., Kazeem, H.M., Umoh, J.U. and Hambolu, D.A. (2014). Dog Ecology and Population Studies in Lagos State, Nigeria. Global Journal of Health Science 6(2): 209 - 220.

16. Hoffmann, B., Freuling, C. M., Wakeley, P.R., Rasmussen, T. B., Leech, S., Fooks, A. R., Beer, M., and Muller, T. (2010). Improved safety for molecular diagnosis of classical rabies viruses by use of a TaqMan Real-Time Reverse Transcription- PCR 'Double Check' Strategy. Journal of Clinical Microbiology. 39703978.

17. Jennifer, w., Susan, M., Taylor, K.L.W., and Brendam, P. O (2007). Rabies in a 10-week-old puppy. Canadian Veterinary Journal 48(9): 931-934

18. Kirandjiski, T., Mrenoski, S., Celms, I., Mitrov, D., Dzadzovski, I., Cvetkovikj, I., Krstevski, K., PicardMeyer, E., Viviani, P., Malinovski, D., Demerson, J.M., Cevtkovikj, A., Davcheva, K., Nakova, E., Mickova, S.T. and Cliquet, F. (2012). First reported cases of rabies in the Republic of Macedonia. Veterinary Record 170: 312

19. Kujul, N.N, Banyigyi, S.A. and Moses G.D. (2010). Rabies in 5-week-old puppies in Jos, Plateau State. Nigeria: A Case Report. Researcher. 2(12), 86-87.

20. Markotter, W., I. V. Kuzmin, C. E. Rupprecht, J. Randles, C. T. Sabeta, A. I. Wandeler, and L. H. Nel. (2006). Isolation of Lagos bat virus from water mongoose. Emerging Infectious Disease 12:1913-1918

21. Mshelbwala, P.P., Ogunkoya and Maikai, B.V. (2013). Detection of rabies antigen in the saliva and brains of apparently healthy dogs slaughter for human consumption and its Public Health implication in Abia State. Nigeria. Veterinary Science, Article ID 468043.

22. Nandi, S. and Kumar, M. (2011). Global perspective of rabies and rabies related viruses: A comprehensive review. Asian Journal of Animal and Veterinary advances 6 (2) 101-116.

23. Noah D.L., Drenzek C.L., Smith J.S., Krebs J.W., Orciari L., Shaddock J., Sanderlin D., Whitfield S., Fekadu M., Olson JG., Rupprecht CE., Childs JE. (1998). Epidemiology of human rabies in the United States, 1980 to 1996. Annal Internal Medicine 128, 922-930.

24. Odeh, L.E., Umoh, J.U., and Dzikwi, A.A. (2014). Assessment of risk of possible exposure to rabies among processors and consumers of dog meat in Zaria and Kafanchan, Kaduna State. Nigeria. Global Journal of Health Science. 61: 142-153.

25. Oduye O. O., Aghomo H. O. (1985). Epidemiology of Rabies in Nigeria Rabies in the Tropics Session V pp 491-496 DOI 10.1007/978-3-642-70060-6_64. Publisher: Springer Berlin Heidelberg; Print ISBN 978-3-54013826-6

26. Offiong, E.E, Ebenso, I., Habib, Ekpo, J.S., Ottoh, A.J, Obioku, E. O., Idiong, N. B. (2013). Rabies in a twoand-half months old puppy in Uyo. A Case Report. International Journal of Science: Basic and Applied Research. 7(1):1-3. 
27. Ojo, A.O., and Adeoye. A. (1967). Rabies in a Nigeria dwarft goat. Bulletin of Epizootic disease of Africa.15, 4: 409-410.

28. Okoh. A.E. (1981). Rabies in farm livestock in Nigeria. International Journal of Zoonoses. 8 (1) 51-56.

29. Oladokun, A.T., Meseko, C.A., Lazarus, D.D. Sati, L.D., Ekong P .S., Nwosuh, C.I. (210). Field Handling and Anti-Rabies Vaccine Efficacy. Nigerian Veterinary Journal 31 (4) 275 - 278

30. Onunkwo, A., Momoh, M.A. and Aderibigbe, B. (1980). Rabies in a six week-old puppy. Nigeria Veterinary Journal. 9: 57-58.

31. ProMED (2012). Public Health Association, Washington D.C. 273-279.

32. Tekki, I.S., Meseko, C.A., Omotainse, S.O., Atuman, Y. J., Chukwukere, Olaleye, S and Okewole, P. A. (2014). Incidence of rabies in domestic animals and consequent risk factors in humans. Medical Microbiology and Diagnosis 3 (3) 143.

33. Tierkel ES, Kissling RE, Eidson M and Habel K (1953). A brief survey and progress Report of controlled comparative experiments in canine rabies immunization. Proc. $89^{\text {th }}$ annual meeting. AVMA, Toronto, Ont.Canada, 443-445.

34. Tsiodras, S., Dougas, G., Baka, A., Billinis, C., Doudounakis, S., Balaska, A., Georgakopoulou, T., Rigakos, G., Kontos, V., Tasioudi, K.E., Tzani, M., Tsarouxa, P., Iliadou, P., Mangana-Vougiouka, O., Iliopoulos, D., Sapounas, S., Efstathiou, P., Tsakris, A., Hadjichristodoulou, C., Kremastinou, J. (2013). Re-emergence of animal rabies in northern Greece and subsequent human exposure, October 2012 - March 2013. EuroSurveillance 18(18):20474

35. Umoh JU, Ezeokoli CD and Okoh EAJ (1988). Rabies and rabies-related viruses In: Viral diseases of animals in africa. Editors A. Olufemi Williams and W.N Masiga. OAU/STRC scientific publication. AOU/STRC and CTA of ACP/EEC (Lome-Convention)

36. Walker, P.J., Firth, C., Widen, S.G., Blasdell, K.R., Guzman, H., Wood, T.G., Paradkar, P.N., Holmes, E.C., Tesh, R.B., Vasilakis, N (2015). Evolution of genome size and complexity in the Rhabdoviridae. PLoS Pathogia 13; 11 (2): e1004664.

37. Webster LT (1939). A mouse test for measuring the immunizing potency of anti- rabies vaccines Journal Experimental Medicine 70:87.

38. Wiktor T J, Sokol E, Kuwert and Koprowski (1969) Immuogenicity of concentrated and purified rabies vaccine of tissue culture origin. Proceeding Society Experimenyal Biology Medicine 131:799-805. 